\title{
Creating Commodities Based on the Design Thinking
}

\author{
By Yuko Oki*
}

The factors that comprised a cluster and the state of inter-organizational networks will differ depending on the nature of the product, but incremental innovation that produces refined high-end products appears to be essential for the continued growth. This study investigates product improvement mechanisms in industrial clusters, using Silicon Valley in the U.S., Cremona in northern Italy, and Jingdezhen in China as case studies, shared by both cutting-edge and traditional clusters. As all of the clusters in this research are at the mature stage, the mechanism of open innovation for new highend products is the key to continue developing these clusters. The aim of this research is to find out the conditions for constructing the product improvement mechanisms in industrial clusters. This research is an empirical study based on specific locations which was conducted from 2005 to 2016. A research framework was developed by conducting a wide survey of advanced research, including both primary and secondary materials. In line with this research framework, combined qualitative and quantitative research was carried out. The qualitative research included participant observations that targeted a small number of cases. As a result, open innovation was found to be essential for product improvement in industrial clusters, and the fact was that business producers contribute profoundly to the construction of that mechanism. By maintaining a balance between an arrangement that ensures competition and cooperation that aims to be of benefit to the whole cluster through this kind of leadership, incremental innovation mechanisms will operate toward product improvement, leading to the sustainable development of an industrial cluster. This comparative study contributed theoretically to the accumulation of empirical studies for the creation of innovation in industrial clusters, and practically to the improvement of the product management by showing common factors for product improvement mechanisms in industrial clusters.

Keywords: Innovation, Creativity, Business Producer, Diamond Model, Communication.

\section{Introduction}

Accumulations of businesses and related organizations in geographically close areas are called "Industrial Clusters". These have been noted as being effective links to product development. Even if a cluster forms, however, it may not necessarily end up delivering high-grade products. Some industrial clusters form but do not lead to product improvements, manufacturing only cheap items instead. The factors that comprise a cluster and the state of inter-organizational networks will differ depending on the nature of the product, but incremental innovation that produces refined high-end goods appears to be essential for the continued growth of a cluster.

${ }^{*}$ Professor, Toyo University, Japan. 
Several studies have examined industrial clusters; the relationship between the region's socio-cultural aspects and the development of clusters (Oliver and Porta 2006), the creation of technology innovations and their spread with clusters (Bell and Albu 1999, Baptista 2000, Mohannak 2007, Mason et al. 2008), but many aspects of the relationship between clusters and innovation have yet to be theoretically clarified; this is an issue for which more empirical studies are needed. Thus, this study investigates product improvement mechanisms in industrial clusters, using Silicon Valley, Cremona, and Jingdezhen as case studies, shared by both cutting-edge and traditional clusters.

The role of big companies has changed in recent years from manufacturing to producing, and their business structures are similar to that of industrial clusters. This comparative study expects to contribute theoretically to the creation of innovation in the industrial clusters, and practically to the improvement of products management, by showing common factors for product improvement mechanisms in industrial clusters.

\section{Literature Review}

\section{Previous Studies on Industrial Clusters}

Research on industrial clusters has garnered interest in a wide range of fields, including spatial economics, economic geography, management strategy theory, organizational theory, network theory, and innovation theory. Industry accumulation was first discussed by Marshall (1890), who found that regional groupings of industries triggered the economic effect of "external economies" through (1) the creation of a market of workers with special skills, (2) the supply of cheap investment resources through the rise of supporting industries and the effective utilization of high-cost machinery, and (3) easier exchanges of information that facilitate the spread of techniques.

Research on industry accumulation picked up during and after the 1980s. Pioneering researchers Piore and Sable (1984) discovered a classic example of "flexible specialization", comprised of the following four regulation functions seen in the manufacturing industry of central and northwestern Italy, also known as the "Third Italy" region: (1) a connection between flexibility and specialization, (2) participation restrictions, (3) an encouragement of competition that drives technological innovation, and (4) a ban on competition that inhibits technological innovation. They argued that a demand for more customized products and services, rapid technological change, and increasing market differentiation led to the need for organizations to combine the economies of scale associated with mass production with a flexible use of production and labor.

Regarding the geographic convergence of industries amid borderless business operations, Krugman (1991), focusing on economic geography, holds that industrial accumulation would arise from an external economy effect. He points out that, when accumulation begins, the external economy effect will become manifest, and the accumulation will gain increased stability. 
From these studies, it is evident that industrial clusters are not merely industry accumulations centered on companies but phenomena that include a wide range of related organizations, like universities and supporting organizations. The geographic proximity aspect of industrial clusters is gaining attention as a factor conditioned by the adhesion of information.

Next, Saxenian (1994) considers America's Silicon Valley as a "regional network model system" and Route 128 as an "independent business model system", arguing that regional industry systems include (1) regional systems and culture, (2) industrial structures, and (3) an internal company structure. She argues that regions should not be perceived as merely an aggregation of the factors of production. Regarding Silicon Valley, Saxenian asserts that individuals create networks that are not confined to companies and that they exchange information, creating a regional network model industry system in which specialized and subdivided companies compete while also cooperating. As a consequence, the companies have been able to flexibly respond to sudden environmental changes.

Porter (1998) calls these accumulations of specific industries "clusters" in terms of management strategy theory. As the superiority of a location fades, the role of the cluster in competition increases in the dynamic economy of the knowledge base. Porter defined a cluster as "a geographically proximate group of interconnected companies and associated institutions particular field, linked by commonalities complementarities" (Porter 1998: 199). According to Porter, a geographic scope of clusters ranges from a region, a state, or even a single city to span nearby or neighboring countries, in addition, clusters include industries and institutions with important linkages or spillovers rather than broad sectors. Porter also states personal relationships, face-to-face communication, and interaction among networks of individuals and institutions influences the cluster. Porter proposes a "Diamond Model" comprised of four factors that form the basis of clusters: demand conditions, component conditions, corporate strategy and competitive environment, and affiliated and supporting industries. The basis of competitive power has increased productivity, and industrial clusters raise productivity through competitive power based on internal "competition and cooperation". The basic concept of the Diamond Model is that clusters have the potential to ignite innovation.

According to Kanai (2003), the difference between Porter's industrial cluster theory and the conventional accumulation theory is that the former offers, (1) in addition to classic factors of production like land, labor, natural resources, and capital, an emphasis on the new factor of knowledge base production, (2) the inclusion of diverse organizations as well as companies and an understanding of the transition to a knowledge-based society, (3) an emphasis on the importance of productivity through innovation, and (4) the identification of the significance not only of cooperative relationships but of competition as well. 


\section{Innovation Research}

Industrial clusters have gone from being perceived as accumulations in which productivity rises due to highly specialized investment resources, information access, complementarity, and affiliated organizations to garnering attention for sparking innovation.

The term "innovation" denotes the act of creating new value by obtaining and applying wisdom generated through human ability (creative originality). Schumpeter (1912), who first identified "new combinations" as the basis of innovation, lists the following items: (1) new product development through creative activity, (2) the introduction of new production methods, (3) new market development, (4) the acquisition of new resources, and (5) organizational reform. Furthermore, drawing from studies on communication patterns in the innovation process, Allen (1977) points out that the presence of "gatekeepers" plays a key role in facilitating the innovation process. The mechanism through which accumulation sparks innovation has not yet been discovered, but Camagni (1991) has introduced the concept of the "Innovative Milieu". He understood that, despite being based on mere geographic accessibility, this milieu is an environment defined by individuals, groups, organizations, and relationships between organizations. Through a budding sense of belonging and through a learning process made possible by accumulation and synergy, the ability to innovate improves throughout the entire milieu.

From an organizational theory perspective, Itami et al. (1998) also identified the inherent mechanisms in industry accumulation as "technology accumulation depth", "lowness of adjustment costs between divisions of labor", and "ease of establishing a business", while also emphasizing the importance of the accumulation's functioning as one "place" (or "ba") that meets the requirements of a dense flow and exchange of information. According to Miyazaki (2005), the "intelligence" and "knowledge" that generate innovation are produced by various creative agents, who are strongly influenced not only by their own "exploration" and "study" abilities but also by their values, the state of the organizations to which they belong, and the atmosphere of the "place".

Teece et al. (1997) showed in his "Dynamic capability theory" that most successful companies have the effective management ability of "Orchestration" of coordinating internal and external resources. Regarding the organization border, Chesbrough (2003) insisted the value creation organically combined ideas both inside and outside as the open innovation. Traditional open innovation was a funnel-like liner model that organizations use to include more stakeholders in their innovation processes. In contrast, open innovation 2.0 (Curley and Salmelin 2013), happens in ecosystems or networks that go far beyond traditional organizational boundaries. Open innovation is a model based on the thought that companies can really benefit from the free bi-directional flow of ideas and innovations from both within and outside the company. The way of manufacturing has also shifted to the perspective of several organizations, individuals, universities, and governments collaborating and participating with one another which helped solve social issues through these networks. 


\section{Methodology}

Research on these kinds of industrial clusters has shifted to an interest in their "place" as a platform in which the economic performance dynamism of knowledge accumulation carries out an exchange of highly sensitive information. However, these include diverse research fields, and studies have not yet theoretically elucidated the relationship between clusters and innovation dynamism; more individual empirical studies are required.

Many different kinds of products are produced in industrial clusters, but, to keep crafting products for premium market segments, mechanisms are needed that incrementally develop high-end products. By taking up a framework in which high-end products drive major market share, a cyclical effect sustains the creation of new, first-time markets. The formation of a cluster alone will not necessarily lead to product improvement; this can be seen in the case of the ceramics cluster in Jingdezhen, China, which was once the pinnacle of luxury but was reduced to one giant cluster centered on popular goods. Especially, in the clusters at the mature stage, open innovation mechanisms become essential for stimulating product sophistication.

Accordingly, this study focuses on the industrial clusters of Silicon Valley in the US, Cremona in Italy, and Jingdezhen in China and examines the product improvement mechanisms shared by both cutting-edge and traditional clusters. As Yin (2009) mentioned, the goal of the case studies is to understand complex social phenomena and real-life events. Because all of the clusters in this research are at the mature stage, the mechanism of open innovation for new high-end products is the key to continue developing the clusters. In addition to a comparative analysis based on the state of competition and cooperation in industrial clusters, this study employed Porter's Diamond Model as a base, which is easy to sort into industry accumulation types and is a valid model for dynamically capturing the sources of innovation that lead to improved products. The fundamental research framework of this study incorporates both of these points of view in the analysis of the interactions in the Diamond Model because it has been found that a concrete network analysis is essential from the perspective of Saxenian's regional industry systems (Harada, 2009, p.39). The research question is what are the conditions for products improvement mechanisms in the industrial clusters, and the results of the research expect the contribution to the application to the innovative management of the clusters and enterprises.

This research is an empirical study based on specific location which was conducted from 2005 to 2016. Details of each case analysis by using the Diamond model were described in previous papers (Oki 2009, 2011, 2014), hence a summary of the analysis will be shown in this paper. A research framework was developed by conducting a wide survey of advanced research, including both primary material (such as interviews and extensive readings of internal material), and secondary material (such as various statistical data). In line with this research framework, combined qualitative and quantitative research was carried out. The qualitative research included participant observations that targeted a small number of cases. This research style, in employing both qualitative and 
quantitative methods, had the advantages of affording both a means of hypothesis discovery and hypothesis verification. These triangulation research methods strengthened the objectivity of the research results.

\section{Product Improvement Mechanisms of Industrial Clusters}

\section{Silicon Valley}

In Silicon Valley, the defense, semiconductor, computer, IT, and biotech industries have advanced as industrial clusters while transforming the environment and their domains. Home to the greatest number of startups in the world, it is also an area with a great concentration of venture capital investment ${ }^{1}$.

The core of Silicon Valley is Stanford University, founded in 1891. Over half of Silicon Valley products are made by companies founded by Stanford graduates ${ }^{2}$. In Silicon Valley, the process of gaining attention locally and acquiring a global market is routine. This process requires effectively aiming for a differentiation of product quality, price, reliability, and functionality in their home turf. In addition to high-level BtoB demand, the need to respond to the expectations of consumers, who demand high standards in the global market of the rapidly popularized internet, drives growth and innovation. Tech developers in Silicon Valley transfer to other companies and often start companies of their own. Most companies use one another more for the creation of new ideas rather than for competition, and they share information, so both people and ideas travel swiftly. The fact that competition benefits the entire cluster is itself an incentive to move to Silicon Valley and start new businesses. The accessibility of fundraising, legal services, and office establishment is attractive to many entrepreneurs, and many of the ideas circulating in the area serve to spur on much of the competition and technological innovation within Silicon Valley companies. Engineers and researchers move in wide social circles, and Silicon Valley has a climate in which people create their own businesses while talking about and sharing ideas and information. Silicon Valley companies are exposed to the need to cooperate to survive, and the objective of constant technological innovation stimulates company efforts.

Amid the active information sharing among researchers in Silicon Valley, the typical methodology in the US is for papers to be published and patents filed at an early stage ${ }^{3}$. The research details are then published, and development is promoted via feedback from the community of researchers. Through this delicate balance of open and exclusive information, rapid development is realized. In

\footnotetext{
${ }^{1}$ Population: 3.05 million, Jobs: 1,592,426. In 2014, there were 14,000 new firms opened in Silicon Valley and more than 600 additional firms moved into the region. Venture capital investment in 2016 was $\$ 9.3$ billion. The funding was heavily concentrated in internet and mobile products and services. (Silicon Valley Index 2017).

${ }^{2}$ It accounts for $\$ 100$ billion for the entire Silicon Valley, $\$ 65$ billion for 100 companies launched by Stanford Alumni. (1996) source Jon Sandelin "Co-Evolution of Stanford University \& Silicon Valley".

${ }^{3}$ Silicon Valley inventors registered 19,000 patents in 2015, which was $13.4 \%$ shares of U.S. (2017 Silicon Valley Index).
} 
Silicon Valley, relationships between companies are not fixed. One can design a product, then look for companies that have the necessary technology, and create new ties. For that reason, "marketing flair for obtaining technical information is also essential"4. This scramble for information is constantly unfolding between companies. This relentless struggle for information requires the ability to draw out new information and to judge the pros and cons of other companies' technology, and this is where product improvement begins.

Silicon Valley professionals have built trusting relationships through their work. This is what leads to the strong, flexible networks of this cluster. For a cluster that attracts diverse parties to expand, it must continuously create platforms that form the source of innovation. To sustainably build these platforms, it is essential to have communication between fellow members made possible by geographic proximity and to create spaces for that communication.

\section{Cremona}

Cremona is the birthplace of Antonio Stradivari, known as the world's greatest violinmaker, and the history of violinmaking in Cremona can be traced back to the 16th century. Cremona's revival as a violinmaking region occurred after the end of the Second World War. The impetus was the establishment of a violinmaking school in 1938, but the results of the school were not immediately evident. It was not until the 1970s that it regained its place as an active producing region. The revival of traditional crafting methods known as "the Cremona style", Cremona has truly been restored as a mecca of violinmaking. In the city of Cremona, over 130 violinmaking workshops and around 500 people are working in the cluster (Oki 2009: 34). Because violinmakers are responsible for everything from production to sales - including pricing, inventory control, and marketingCremona also represents an accumulation of entrepreneurs.

Because of the completely handmade instruments, on average, each artisan can make approximately between 8 to 12 violins per year (Oki 2009: 176). A certain volume is necessary in order for the brand to penetrate the market, and this distribution volume is met through the accumulation of workshops and the creation of an industrial cluster. Since its establishment, the violinmaking school's doors have been wide open to foreign students, and the development of sales routes in the countries of its international students has led to the global expansion of Cremona. Because top-performing musicians tend to use Old Italian violins like Stradivari or Guarneri, modern Cremona instruments have had to target mid-level users like amateurs and music students rather than high-end users. This has led to massive orders from dealers and music stores, and buyer demand for instruments that are easy to sell has also raised production standards. In this way, Cremona's product improvement developed especially from the perspective of the market point of view, through the foundation of the craftsmanship of the violinmaking school, while customer creation has advanced under the leadership of dealers and music stores.

${ }^{4}$ Prof. Dr. Seishi Takeda, Director of JSPS in SF. 
Cremona's diversity is apparent even in the three famous masters who act as gatekeepers. With the arrival of artisans who are passionate not only about their craft but also about sales and teaching, space has been created for this dynamic network. The pursuit of each individual musical instrument artisan is not only about the craft; the connection to all related industries is the key to the dynamism of Cremona.

However, Cremona faces several issues. The establishment of the violinmaking school and its open-door policy toward foreigners have created a "Wimbledon effect", and competition has spread around the world. Consequently, artisans who have spun off from Cremona are now scattered around the globe and are giving Cremona a run for its money in terms of production volume. Because Cremona is open about skills, violins made in other parts of the world have come to resemble Cremona instruments so closely that the two types are indistinguishable. With the establishment of the violinmaking school, extremely sensitive information about the violinmaking craft was able to shift from "tacit knowledge" to "explicit knowledge," but now the Cremona needs to strengthen the tacit knowledge that leverages its geographic conditions and allow for face-to-face exchanges of information. Along with improving products through open innovation involving high-end users, Cremona needs to pursue its own individuality as a region in order to maintain its competitive edge.

\section{Jingdezhen}

Jingdezhen is a preeminent ceramics industrial cluster in China. In Jingdezhen, which is endowed with high peak clay and firewood, used as raw materials for porcelain, ceramics production began in the Han period (206BEC- 220CE). From the Song and through the Ming (1368-1644) and Qing dynasties (1644-1912), porcelain production in the golden age involved ceramics with blue patterns on a white background that were made in government kilns. Through state-run, massproduction factory systems after the start of the People's Republic of China and through the Cultural Revolution, which tried to create a new socialist culture, the former sophisticated industrial art almost ceased to exist, and the current Jingdezhen ceramics industry appears to be something entirely different from what it was in the bygone age of prosperity.

Large to small factories represent a combined total of about $5,000^{6}$. Under state-led cultural policies and funding assistance from the local government, the Jingdezhen Ceramic Institute, which teaches tradition, techniques and trains mass producers, combines the ease of procuring raw materials with an entrepreneurial climate. It attracts "living national treasure ceramic artists" (Oki 2014: 13) and the Jingdezhen Ceramic Institute faculty members and establishes production requirements for the cluster (Oki 2014: 12). The cluster features open skillsharing internally (with no feelings of guilt about copying), and two classes of product: mass-produced items and works of art (the works of art are further

\footnotetext{
${ }^{5}$ When an industry is primarily domestically owned, but easing of foreign ownership restrictions allows the economy to benefit from foreign investment and increased global competition.

${ }^{6}$ China Press (2013.1.21).
} 
classed into replicas of old works and new works). To meet large orders within the country, assembly-line production systems and independent sales routes have been established that center on locality and blood relationships (Fang 2004).

The former splendor of the Jingdezhen ceramics industry was reorganized into massive factories under a planned economy. Despite the continued meticulous production of high-grade replicas of old works, production since the Cultural Revolution has been permitted only in the form of public service. In the background of the recent lack of progress in product improvement, China is recognized as being in a state of upheaval because of its rapid economic development, in which the goal of craftsmanship is the ability to sell at a high price rather than maintain product quality. Because success is equated with profit, although selfishly cooperative activities predicated on economics can be seen, there is no general concept of altruistic cooperation based on the greater good of the entire cluster. The standards for high-grade products are unclear, and products are ultimately judged more on price rather than on quality. Because of the direct connection between social status and price, it is difficult to change prices in a meaningful way, even through mutual competition and peer reviews do not lead to product improvement.

Though, Jingdezhen is now attempting a renaissance as a ceramics producing region while planning collaborations between the government and private businesses. This change is symbolized by the group of art galleries recently developed at the site of the state-run factories and in the large-scale establishment of the Jingdezhen China Ceramics Museum opened in 2017.

\section{Findings from Case Studies}

\section{Silicon Valley}

The development of Silicon Valley's sophisticated products is driven by the active innovation strategies of leading companies like Apple, Intel, Google, Cisco Systems, and Facebook, to name a few. The heads of these companies take a leading role in designing new products and services. From the fact that they use Silicon Valley's business networks and supply the necessary parts from companies with the right skills to complete their products, one can see that these large companies serve as "business producers" that drive high-end production in Silicon Valley. More than anything, the continual creation of such business producers is the hallmark of Silicon Valley. The creative climate of Californian freedom, where people prefer things to be a bit different, is fertile ground for coming up with ideas for new enterprises, products, and business models. Silicon Valley specializes in the materialization of ideas no one has yet imagined rather than working to grasp market needs. In this sense, Silicon Valley producers epitomize a product-oriented way of thinking.

Many of the people involved in research and development in Silicon Valley graduated from top-tier universities both within and outside the US, including Stanford University. Born into affluent households, they were brought up 
surrounded by extravagant things. They have a deep knowledge of culture, are accomplished in musical instruments, and have a discerning eye for works of art. People raised in this way gather in Silicon Valley, and, surrounded by the wild expanse of nature in America, they enjoy sports and artistic activities in their everyday lives, while holding parties for their friends at the top income levels of society, therefore enjoying the best that life has to offer. In this lifestyle, they share interests from reviews of new local restaurants to opera, classical music, and collections of artworks plus fine wine. The people in these networks not only share specialized knowledge of the technology they use on the job but also polish each other's aesthetic senses. It is only natural that people who live in this cluster seek beautiful products. The combination of technology and sensitivity built by these networks of sophisticated professionals acts as the source of Silicon Valley's open innovation and fosters product improvement.

\section{Cremona}

In Cremona, although participation by dealers and music stores is strong, participation from musicians is lacking ${ }^{7}$. The "Cremona style" considered to be the Cremona tradition was found to be nothing more than a business catchphrase. Stradivari's production methods have not been inherited by the Cremona of today. Cremona's product improvement efforts have been chasing after "form" because of the business-related concerns of business producers from outside the cluster (e.g., dealers, large-scale music stores). But it is also true that because there exists outside business producers, manufacturers do not have any stock in their workshops as the business producer buy up stock instantly due to high demand from consumers, consequently, manufacturers have been able to give their undivided attention to only violin making. As a network has been built that brings in market information from outside the area and influences product planning and since the knowledge and skill accumulation that builds up in the region has not been stuck in an exclusive space, Cremona has been able to implement open innovation leading to product improvement.

However, Cremona, which has seen decent product improvement thus far, needs to aim even higher. If Cremona is to make use of its "space" as a platform for information, resources and move into open innovation, it must further encourage direct participation from performers with strict demands and standards and make high value-added products that are not only beautiful but also bring out the absolute best of a performer's musical expression. Dealers and music stores demand instruments in the middle price range that they can sell in quantity, and they are concerned about appearance. Cremona has strong ties with these business producers, and daily guidance from the masters also tends toward "form" rather than "sound" in order to make instruments that will sell. However, the

\footnotetext{
${ }^{7}$ Violin makers who have unique dealers was $57.6 \%$ (average of five dealers) and $67.2 \%$ of violin makers think that musicians does not bring much information into Cremona.

${ }^{8} 41.4 \%$ answered that they would like to pay attention to the sound, and $57.1 \%$ answered both the shape and the sound, while $1.4 \%$ answered the sound; more craftsmen would like to pay attention to the sound rather than the shape.
} 
violin is a musical instrument, and its end user, the performer, seeks a beautiful sound. Based on this reality, business producers need to be inside the cluster as well in order to achieve further product improvement. The cluster needs business producers who create high-level products that connect craftsmanship to society, rather than those who are focused on sales.

\section{Jingdezhen}

Many workshops produce works of art and daily necessities, but, because each person works on his or her own, the circumstances are not suited to product improvement as a cluster. Without the presence of companies or people to take on a leadership role in Jingdezhen, only individual innovation has come to be expected. The process of handing down skills as an accumulation of knowledge has been neglected. Overall balance is of the utmost importance for decorative art products, but, because the system of purchasing half-finished goods and decorating them in an assembly line is the norm, few artists combine all of the steps and work to create finished products. Thus, the works lack artistry overall. Even so, since expensive items could be sold as gifts, Jingdezhen's large-scale ceramics cluster could survive. However, nowadays due to the change of political regulations: gifts exchanges between bureaucrats have been prohibited, therefore such kinds of artistic products have dramatically decreased in sales.

As Jingdezhen's cluster development progresses politically and energetically under government leadership, the government will be seen as the role of the business producer. The government administration will establish a production environment, but it will not necessarily be directly involved in product design. However, boldly implemented policies are attracting young people. By stimulating competition and cooperation, if a new orientation for the cluster can be discovered, perhaps the people who make a living there will not be left out in the cold but will be able to pursue a production that makes use of their skills. The current bearers of innovation are not the leading ceramic artists who have striven to make money; that torch is being passed down to talented young people who possess a worldly sensitivity and are brimming with vitality. The construction of a cluster fit for product improvement is essential for market creation. Because the cluster has entered a time in which individuals can separate from the group and create unique works and when information from other places has become easy to obtain, by securing a competition structure while constructing cooperative relationships that leverage internal and external networks, this cluster must spark open innovation that combines craft and artistry to restore its place as a great ceramic producing region once again. 


\section{Discussion}

\section{Conditions Allowing Product Improvement Mechanisms to Function}

It is evident from the research that some conditions are needed for product improvement mechanisms to work. Although the cases involve both cuttingedge and traditional industrial clusters with differences in structure and product, they have several points in common. Based on these case analyses, the hypothesis of conditions were extracted for product improvement mechanisms in industrial clusters are, (1) leadership by business producers who combine skills and creativity, (2) peer review, (3) discernment of high-end users, (4) and the sensitivity of tech people or artisans.

\section{Leadership by Business Producers Who Combine Skills and Creativity}

What is important in craftsmanship is that those at the top level have their own production philosophies and that they are well-versed in the craft. In organizations of professional craftspeople and artisans with advanced techniques, when the top-level actors are well-informed about the craft and demonstrate a vision based firmly on their own sensitivity, the acceptance of strict standards will begin to flow and be understood on the factory floor, and innovation can be expected through setting goals and working to achieve them.

In Silicon Valley, large companies acting as business producers take on a leadership role, which drives development. Apple is an exceptional example of this. By having senior management test the user-friendliness of products in the middle of development, the company has been able to create products with well-crafted designs and quality user-friendliness. For product development decision-making, when the president of a tech company becomes excited over craftsmanship, the company blends craft, sensitivity, and innovation continually emerges.

In Cremona, master violinmakers acting as leaders in the cluster drive the craft while cooperating with dealers and large music stores that act as external business producers. They are primarily Italians with a very refined aesthetic sense. Each master studies his or her own different crafting methods, but that enthusiasm creates the approach of artisans earnestly striving at violinmaking while exemplifying the course that the cluster should take. They often give advice about the production process for the instruments of artisans who fall under their apprenticeship lineage, and they can persuade stubborn artisans to change because of their own experiences in production and trial and error and are able to guide the cluster toward product improvement that is obsessed with beauty.

In Jingdezhen, most are small businesses, and both artisans and companies are fundamentally self-reliant. Skilled ceramic artists and the faculty of the Jingdezhen Ceramic Institute drive the cluster. Due in part to the absence of wholesalers, however, they have no choice but to develop their own sales routes and focus on trade. In this state of affairs, there continues to be an absence of 
leadership, and the products of this cluster have not been suited to improvement. It is unfortunate that the extraordinary works of the past have not been leveraged in these products. Through the appearance of business producers with a strong sense of leadership, it can be expected that craft and artistry will be combined once again in the future.

\section{Peer Review}

The merit of an industrial cluster is that there are many spaces for peer review within reach every day, and these lead to product improvement. One's own dedication is important for refining professional skills, but evaluations by professionals in the same trade are also essential opportunities for legitimate recompense for one's efforts.

Silicon Valley has two types of companies: technology companies and companies that function as business producers. The technical information of each tech company is exposed and evaluated under strict peer review. Because of the large assembly of tech developers and the formation of a community with specialized knowledge, highly reliable information circulates, and product improvement is realized.

In Cremona as well, peer review is indispensable to product improvement. Through routine visits with fellow craftspeople, both masters and classmates at violinmaking school, artisans have ample opportunity to see their rivals' instruments. If one makes a low-quality instrument, it will be talked about immediately within the small community. Respect in Cremona is not based on high pricing. In addition to official violinmaker networks and violin making competitions like those at the Triennale, routine peer reviews by colleagues raise artisans' motivation to improve their work.

Contrariwise, Jingdezhen is not making use of spaces for peer review. Jingdezhen does have opportunities for peer review, such as at the International Ceramics Festival, but this is treated as a space for business and has not been effectively used to improve technical skills. Trade associations are also nonfunctioning. Since success is equated with money-making, standards for product improvement are vague, and artisans have aimed to sell products at high prices rather than improve quality. For this reason, though there are spaces for peer review, they have not motivated artisans to make use of these opportunities for product improvement because the structure of the system is not one in which improved quality is reflected in higher prices. Naturally, with more craftspeople with high awareness among students and young people, perhaps a trend will emerge of proactively leveraging spaces for peer review.

\section{Discernment of High-end Users}

To improve a craft for even more product improvement, high-level demand from high-end users is indispensable.

In Silicon Valley, where BtoB is mainstream, companies are the high-end users. It goes without saying that the technology of other companies that will 
be used for product development leading to big business will be assessed very deliberately. Business producer companies use the technology of other companies as a foundation for completing the products they had in mind while making ever more high-level demands, evolving the manufacturing development skills of component makers in the process. As product development is carried out to meet the strict demands of individual users, consumers also become drivers of tech development.

In Cremona, because of the focus on product lines targeting the middle class, direct demand from violinists is not very high. The biggest customers are dealers and music stores. These clients have many demands for form in particular (e.g., shape, color), as they want makers to produce instruments that will sell. If more musicians participated in Cremona's instrument industry, the demand for good sound would also increase, and perhaps Cremona instruments would be used by a greater proportion of top-level musicians. At present, however, highend users are not buying these instruments.

In Jingdezhen, even high-end users have not developed a discerning eye because generations have focused on gift exchanges between bureaucrats. However, as economic development quiets down, there will start to be more room for cultural aspirations. Chinese works are being enthusiastically bought up at auctions overseas, famous works from the past are being curated within the country, and public and private museums are being built one after another, creating more and more spaces in which to appreciate works. In this way, the discernment of ostensibly cultured high-end users is being refined.

\section{Creativity of Tech People or Artisans}

The final important point for sophisticated manufacturing is the sensitivity of tech people and artisans on site. No matter how wonderful the top management is, those who actually move development forward are the craftspeople. Their sensitivity is a decisive factor in product improvement.

Cultural activities abound in Silicon Valley. At Stanford University, elites with educated tastes excel at playing instruments even as they major in other fields, stopping in for lessons at the music department in addition to their studies, and holding two-hour recitals before they graduate. These talented people start working in professional jobs while still contributing to artistic activities in the area. A feature of Silicon Valley is that even those who do not directly contribute to artistic activities may have family members who do, and there is an abundance of chances to enjoy the arts, with many high-quality events regularly held there.

Cremona is an Italian town with a thoroughly discerning taste in aesthetics. Italians have world-class taste, and the long history of the town is revealed in beautifully carved buildings. The spirit of careful selectiveness about aesthetic detail also spreads to the foreigners who live in Cremona and is engraved into the everyday sense of things.

In Jingdezhen, both ceramic artists and artisans have had few opportunities to see the genuine works of their own hometown. There is an abundance of eccentric works of art, replicas of old works, and low-quality popular goods. In 
factories that use an assembly-line system, even though individual workers are highly skilled, their work is done while they are distracted, and the products do not convey a sense of spirituality. Artisan sensitivity is not something that can be cultivated in the short term. However, if museums are built and Jingdezhen Ceramic Institute graduates compete to produce works from a global point of view, these may lead to product improvement for the cluster.

\section{Conclusions}

The significance of this study is its attempt to grasp the product improvement mechanisms underlying both cutting-edge and traditional industrial clusters. From among these, this study extracted the conditions as a hypothesis suited to product improvement. In the Silicon Valley and Cremona cases, open innovation was found to be essential for product improvement in industrial clusters, and the fact was that business producers contribute profoundly to the construction of that mechanism. By contrast, in the formerly prosperous Jingdezhen, product improvement has not advanced because the absence of these functions led to the prioritization of competition, which emerged because the establishment of cooperative relationships that would have generated innovation to the benefit of the entire cluster had not been encouraged. Even if each actor in the cluster should be allowed to be an autonomous professional, business producer's leadership is needed that can leverage the skill and sensitivity of artisans and connect them to the needs of high-end consumers. By maintaining a balance between an arrangement that ensures competition and cooperation that aims for the benefit of the whole cluster through this kind of leadership, incremental innovation mechanisms will operate toward product improvement, leading to the sustainable development of the industrial cluster.

Many previous studies about industrial clusters tried to discover the mechanism through which accumulation sparks innovation, however it has not yet to be theoretically clarified. Therefore, more empirical studies are needed, and these three comparative case studies contribute to the accumulation of the construction of the theories between clusters and innovation. The limitation of this research is that the factors that comprise of a cluster and the state of interorganizational networks will differ depending on the nature of the product, hence, further research is needed for the construction of this innovation theory. Though, the accumulation of incremental innovation that produces refined high-end goods appear to be essential for the continued growth of a cluster. The explication of mechanisms could lead to the thought-provoking process for the further development of industry and also for the innovative management of the enterprises. 


\section{References}

Allen TJ (1977) Managing the Flow of Technology, MIT Press, Mass.

Baptista R (2000) Do innovations diffuse faster within geographical clusters? International Journal of Industrial Organization 18: 515-535.

Bell M, Albu M (1999) Knowledge System and Technological Dynamism in Industrial Clusters in Developing Countries. World Development 27(9): 1715-1734.

Camagni R (1991) Local 'milieu', uncertainty and innovation networks: towards a new dynamic theory of economic space. In Camagni R (ed) Innovation Networks: Spatial Perspectives, 121-142. London: Belhaven Press.

Chesbrough HW (2003) Open Innovation: The New Imperative for Creating and Profiting from Technology. Boston: Harvard Business School Press.

China Press (2013.1.21) IT. Jingdezhen: Over 5000 ceramic companies. Unitedspace Inc, Tokyo.

Curley M, Salmelin B (2013) Open Innovation 2.0: A New Paradigm. OISPG White Paper, European Commission.

Fang L (2004) Yingdezhen in China: the rising and development of private ceramics industry. Bunmei 21(17): 91-105.

Harada S (2009) Porter no sangyo cluster ron. [Porter's industrial cluster theory]. Nagaoka University Research Journal 7: 21-42.

Itami H, Matsushima T, Kikkawa T (eds) (1998) Sangyo syuseki no honshitsu: Junan na bungyo, syuseki no jyoken. [The essence of industrial cluster]. Tokyo Yuhikaku.

Joint Venture Silicon Valley, Silicon Valley Institute for Regional Studies (2017) 2017 Silicon Valley Index, Joint Venture Silicon Valley, California.

Kanai K (2003) Cluster Riron no Kentou to Saikousei-Keieigaku no Shiten kara. [Investigation and Reconstruction of Cluster Theory]. In Ishikura Y, Fujita M, Maeda N, Kanai K, Yamasaki A Strategy for Cluster Initiatives in Japan, 43-73. Tokyo: Yuhikaku Publishing.

Krugman P (1991) Geography and Trade. MIT Press paperback ed., Cambridge, MIT Press, Mass.

Marshall A (1890) Principle of Economics. London: Mac Millan and Co.

Mason C, Castleman T, Parker C (2008) Communities of enterprise: developing regional SMEs in the knowledge economy. Journal of Enterprise Information Management 21(6): 571-584.

Miyazaki T (2005) Historical context from the industrial clusters theory to the cluster theory. Research Paper Series of Sensyu Univerisity Center for Urban \& Regional Policy Institute 1: 265-288.

Mohannak K (2007) Innovation networks and capability building in the Australian high-technology SMEs. European Journal of Innovation Management 10(2): 236251.

Oki Y (2009) Violin making in Cremona. Tokyo: Bunshindo.

Oki Y (2011) The history of Silicon Valley: the social capital on developing industrial cluster. Kyoto Management Review 18: 35-59.

Oki Y (2014) Innovation in the industrial cluster in Jingdezhen. Kyoto Management Review 24: 1-29.

Oliver JLH, Porta JID (2006) How to measure IC in Clusters: empirical evidence, Journal of Intellectual Capital 7(3): 354-362.

Piore MJ, Sable CE (1984) The Second Industrial Divide: Possibility for Prosperity. New York: Basic Books.

Porter ME (1998) On Competition. Boston: Harvard Business School Press. 
Sandelin J (2007) Co-Evolution of Stanford University \& Silicon Valley 1950 to Today. Stanford University, Office of Technology Licensing.

Saxenian A (1994) Regional Advantage: Culture and Competition in Silicon Valley and Route 128. Cambridge: Harvard University Press, Mass.

Schumpeter J (1912) English translation published in 1934, The Theory of Economic Development. Cambridge: Harvard University Press.

Teece DJ, Pisano G, Shuen A (1997) Dynamic capabilities and strategic management. Strategic Management Journal 18(7): 509-533.

Yin RK (2009) Case Study Research: Design and methods, Sage, CA. 
